\title{
Identification of a novel GPR143 mutation in a large Chinese family with congenital nystagmus as the most prominent and consistent manifestation
}

\author{
Jing Yu Liu $\cdot$ Xiang Ren $\cdot$ Xiufeng Yang $\cdot$ Tangying Guo $\cdot$ \\ Qi Yao $\cdot$ Lin Li $\cdot$ Xiaohua Dai $\cdot$ Mingchang Zhang · \\ Lejin Wang $\cdot$ Mugen Liu $\cdot$ Qing K. Wang
}

Received: 27 January 2007/Accepted: 2 April 2007/Published online: 22 May 2007

(C) The Japan Society of Human Genetics and Springer 2007

\begin{abstract}
Congenital nystagmus is characterized by involuntary, rhythmical, repeated oscillations of one or both eyes. We studied a large Chinese family with nystagmus as a prominent and consistent manifestation phenotype in nine patients to map and identify a diseasecausing gene for nystagmus. X-linked recessive inheritance was observed in the family, and foveal hypoplasia was detected in some of the nine patients. The disease gene was mapped to an approximately $10.6 \mathrm{Mb}$ region flanked by DXS996 and DXS7593 on Xp22 with a significant peak multipoint LOD score. Analysis of 21
\end{abstract}

J.Y. Liu and X. Ren contributed equally to this work.

J. Y. Liu $\cdot$ X. Ren $\cdot$ Q. Yao $\cdot$ X. Dai $\cdot$ M. Liu $(\bowtie) \cdot$

Q. K. Wang $(\bowtie)$

Center for Human Genome Research and College of Life

Science and Technology, Huazhong University of Science and Technology, Wuhan 430074, People's Republic of China e-mail: qkwang@mail.hust.edu.cn

M. Liu

e-mail: lium@mail.hust.edu.cn

X. Yang $\cdot$ T. Guo

Development of Proof-Testing, Renmin Hospital of Tanghe,

Tanghe, Henan, People's of Republic of China

L. Li · Q. K. Wang

Department of Molecular Cardiology, Lerner Research Institute, Cleveland Clinic/NE40, Cleveland, OH 44195, USA

M. Zhang

Department of Ophthalmology, Union Hospital,

Huazhong University of Science and Technology, Wuhan,

People's Republic of China

L. Wang

Eye Center, Peking University, Beijing,

People's Republic of China candidate genes in the region revealed a novel p.S89F mutation in the second transmembrane domain of GPR143, a G protein-coupled receptor which causes ocular albinism when mutated. All male patients in the family were hemizygous for the mutation; the female carriers were heterozygous for the mutation. The p.S89F mutation was not identified in 100 normal females or 100 normal males. Our results indicate that a mutation in the GPR143 gene can cause a variant form of ocular albinism, with congenital nystagmus as the most prominent and only consistent finding in all patients in this Chinese family. These results expand the spectrum of clinical phenotypes associated with GPR143 mutations.

Keywords Congenital nystagmus and consistent manifestation - GPR143 - Mild ocular albinism . Linkage analysis $\cdot$ Mutation

\section{Introduction}

Congenital nystagmus $(\mathrm{CN})$ is a common oculomotor disorder with a frequency of 1/1,500 live births (Patton et al. 1993). It is characterized by bilateral uncontrollable ocular oscillations, reduced vision, and onset typically at birth or within the first few months of life. Patients' oscillations can be horizontal, vertical, or torsional, or any combination of these, although horizontal are the most common (Patton et al. 1993; Preising et al. 2001; Zhang et al. 2005). Reduced vision and poor depth perception are the major symptoms of patients with nystagmus. The etiology or molecular pathogenic mechanism of $\mathrm{CN}$ is largely unknown.

Multiple inheritance patterns have been described for $\mathrm{CN}$, including $\mathrm{X}$-linked dominant and $\mathrm{X}$-linked recessive 
(MIM 310700), autosomal dominant (MIM 164100), and autosomal recessive (MIM 257400) forms (Kerrison et al. 1999). Among these types, X-linked inheritance is the most common type, and two genetic loci for X-linked $\mathrm{CN}$ have been mapped to Xp11.3-11.4 and Xq26-q27, respectively (Cabot et al. 1999; Guo et al. 2006; Kerrison et al. 1999; Zhang et al. 2005). Xq26-27, also known as NYS1, is the most common locus; the responsible gene has recently been identified as a FERM domain-containing 7 gene (FRMD7) (Tarpey et al. 2006). Although three genetic loci for the autosomal dominant form have been mapped to chromosomes 6p12, 7p11.2, and 13q31-q33 (Klein et al. 1998; Kerrison et al. 1996, 1998; Ragge et al. 2003), the specific genes at these genetic loci have not yet been identified.

Nystagmus can also occur in the setting of other retinal diseases, including ocular albinism resulting from mutations in the GPR143 gene, also known as OA1, encoding a G-protein-coupled receptor, and X-linked congenital stationary night blindness, caused by mutations in a calcium channel gene CACNAIF (Gottlob 2001).

We have identified and characterized a large six-generation Chinese family with X-linked recessive nystagmus. Nine individuals in the family are affected, all males. In addition to nystagmus some patients also suffer from foveal hypoplasia, myopia, amblyopia, and astigmatism. Linkage analysis of the family mapped the disease-causing gene to Xp22.11-Xp22.32 with a significant multipoint LOD score of 8.89. Mutation analysis of candidate genes in the region suggested that a novel mutation in the GPR143 gene causes the disease in the family.

\section{Subjects and methods}

Study subjects and isolation of human genomic DNA

The study participants were identified and enrolled at the People's Hospital of Nanyang County, Henan province, P.R. China. Informed consent was obtained from the participants in accordance with study protocols approved by the Ethics Committee of Huazhong University of Science and Technology. This study adhered to the tenets of the Declaration of Helsinki.

The participants were clinically examined at the People's Hospital of Nanyang County, the Eye Center of Peking University, and the Union Hospital of Huazhong University of Science and Technology. Ocular examinations were performed by slit lamp biomicroscopy and direct and indirect ophthalmoscopy.

DNA was extracted from peripheral whole blood by use of a Wizard Genomic DNA Purification Kit (Promega, Madison, WI, USA).
Linkage and candidate genes mutation analysis

Linkage analysis of the genotyping data was performed as described elsewhere (Wang et al. 2005). Genotyping was performed using 33 polymorphic markers covering the entire $\mathrm{X}$ chromosome. Eighteen markers that span the $\mathrm{X}$-chromosome by every $10 \mathrm{cM}$ were from the ABI Prism Linkage Mapping Set MD10 (performed as instructed by the manufacturer). The other markers were identified from the Marshfield Medical Genetics database (http:// research.marshfieldclinic.org/genetics/) and used for fine mapping. The disease was specified as an X-linked recessive trait with penetration of $99 \%$ in males. We assumed a gene frequency of 0.00001 . Pairwise logarithms of the odds (LOD) scores and multi-point LOD scores were calculated with the Linkage Package 5.2 software.

Mutation analysis was conducted for all exons and exon-intron boundaries of candidate genes using direct DNA sequence analysis (Wang et al. 2005).

Restriction fragment length polymorphism (RFLP) analysis

The wild type allele contains a $B s l \mathrm{I}$ restriction site, and mutation $266 \mathrm{C} \rightarrow \mathrm{T}$ (GenBank accession number: Z48804) disrupts this site. This enabled use of RFLP analysis to confirm the mutation and to test whether the mutation co-segregated with the disease in the family. Exon 2 of GPR143 containing the mutation was PCRamplified for all members of the family and for 200 (100 males and 100 females) unrelated healthy Chinese individuals, as described above. The 237-bp PCR product was digested with 1 unit $B s l \mathrm{I}$ (NEB, USA) at $37^{\circ} \mathrm{C}$ overnight, and the resulting digestion products were separated on $2.5 \%$ agarose gel. The wild-type product can be cut by BslI and yielded two bands of 144 and 93-bp. The mutant product cannot be cut by BslI, and only one 237-bp band was observed after electrophoresis.

\section{Results}

Clinical characterization of patients

We identified a large, six-generation, non-consanguineous Chinese family with 36 living members, among whom were eight living patients with nystagmus (Fig. 1A). Investigation of family history revealed one deceased member had also had nystagmus. All affected individuals were males, and the inheritance pattern of the disease in the family was typical X-linked recessive (Fig. 1A).

The proband (Fig. 1A, V-10) developed nystagmus with the horizontal oscillation before the age of six months. The 
Fig. 1 A The pedigree structure of a Chinese family with $\mathrm{CN}$. The proband is marked with an arrow. The family members participating in both clinical and follow-up mutation analysis are indicated by asterisks. B Iris and fundus photos from mutation carrier IV-14 $(a, c)$ and the proband $\mathrm{V}-10(b, d)$
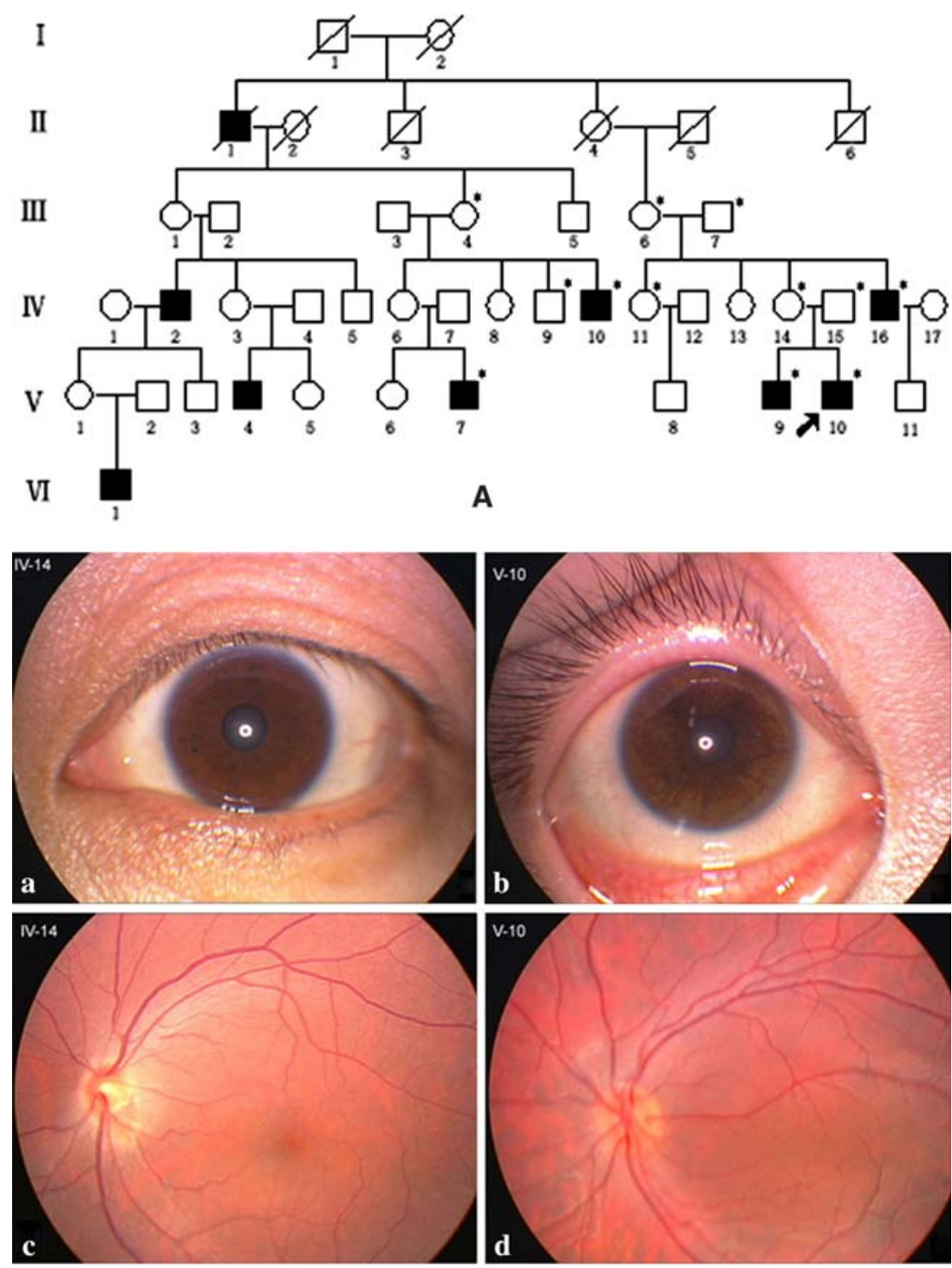

B patient later developed astigmatism and amblyopia. The visual acuity of right and left eyes was 20/60 and 20/50, respectively. Examination of the iris revealed clear veins and normal response to the light (Fig. 1B, b). Fundus examinations revealed the clear-cut boundary of optic disc, normal distribution of blood vessels, and retina pigmentation (Fig. 1B, d). Foveal dysplasia was identified in the proband (Fig. 1B, d) and three other patients (IV-10, IV-16, V-9) (data not shown). In the skin and hair of these patients pigmentation was normal.

Patients IV-10, IV-16, V-7, and V-9 and obligate female carrier IV-14 were also characterized clinically (Fig. 1; Table 1). Pigmentation of skin and hair was normal. The pigments in the macula were clear and regular in patients IV-10 and carrier IV-14, but not in patients V-9 and IV-16. The myopia arcs were present in patients V-9, IV-16, and carrier IV-14 (Fig. 1B, c; Table 1). The female carriers in this family had normal visual acuity, except for carrier IV-14, and were free from nystagmus.

Genetic linkage analysis

Analysis of the pairwise LOD scores identified positive linkage to marker DXS987 with a peak LOD score of 1.81 at a recombination fraction of 0 (data not shown). Additional markers flanking DXS987 were genotyped in the family and the genotyping data were used for multipoint LOD score linkage analysis. Multipoint LOD scores reached a significant level and a peak multipoint LOD score of 8.89 was obtained at DXS987 (data not shown). Our results suggest that the clinical phenotype in the family under study is linked to DXS987 on Xp22. The result of 
Table 1 Clinical characteristics of five affected males (IV-10, IV-16, V-7, V-9, V-10) and one carrier (IV-14) in a Chinese CN family with GPR143 mutation p.S89F

\begin{tabular}{|c|c|c|c|c|c|c|c|c|c|c|}
\hline \multirow[t]{2}{*}{ ID\# } & \multirow[t]{2}{*}{ Age } & \multirow[t]{2}{*}{$\mathrm{CN}$} & \multirow{2}{*}{$\begin{array}{l}\text { Iris } \\
\text { (a) }\end{array}$} & \multicolumn{5}{|c|}{ Fundus phenotype } & \multirow[t]{2}{*}{ VA (R/L) } & \multirow[t]{2}{*}{ Astigmatism } \\
\hline & & & & $\mathrm{b}$ & $\mathrm{c}$ & $\mathrm{d}$ & $\mathrm{e}$ & $\mathrm{f}$ & & \\
\hline IV -10 & 26 & + & + & + & - & + & + & - & $\begin{array}{l}20 / 40 \\
20 / 60\end{array}$ & + \\
\hline IV-16 & 31 & + & + & + & + & - & - & + & $\begin{array}{l}20 / 650 \\
20 / 200\end{array}$ & + \\
\hline $\mathrm{V}-7$ & 3 & + & + & + & - & + & - & - & $\begin{array}{l}20 / 40 \\
20 / 50\end{array}$ & + \\
\hline V-9 & 18 & + & + & + & + & - & - & + & $\begin{array}{l}20 / 200 \\
20 / 250\end{array}$ & + \\
\hline $\mathrm{V}-10^{*}$ & 18 & + & + & + & + & + & - & - & $\begin{array}{l}20 / 60 \\
20 / 50\end{array}$ & + \\
\hline IV-14 & 40 & - & + & + & + & + & + & + & $\begin{array}{l}20 / 200 \\
20 / 200\end{array}$ & - \\
\hline
\end{tabular}

ID\# is the patient identification number in Fig. 1A. Age is the age of diagnosis in years. $\mathrm{CN}$, congenital nystagmus; VA, visual acuity. *Patient V-10 had amblyopia

a Normal iris, normal response to light and normal pigmentation (+ yes; - no)

b Clear boundary of disc (+ yes; - no)

c Mottling retina pigmentation (+ yes; - no)

$\mathrm{d}$ Clear and neat pigmentation in macula $(+$ yes; - no)

e Existence of reflex light in fovea centralis $(+$ yes; - no)

f Myopia arc (+ yes; - no)

haplotype analysis defined the boundaries of the disease locus between DXS996 and DXS7593, a region of approximately $10.6 \mathrm{Mb}$.

\section{Identification of a novel mutation in GPRI43}

Twenty-one genes located in the disease locus were analyzed as the candidate genes for nystagmus on the basis of their potential physiological functions and their expression in the nervous system. Direct sequence analysis revealed mutation of a $\mathrm{C}$ to $\mathrm{T}$ transition at nucleotide 266 of GPR143 (or OA1; GenBank accession \# Z48804) in the proband and his mother (carrier) (Fig. 2a). The mutation leads to a substitution of a highly conserved amino acid residue serine with a phenylalanine residue at codon 89 (p.S89F). Detection of mutation p.S89F was further confirmed by RFLP analysis which showed the presence of the hemizygous mutant allele (237-bp band) in male patients IV-2, V-1, V-2, and IV-6 (Fig. 2b), both wild type and mutant alleles (143 and 94 bps bands) in female carriers (individuals III-1, III-2, IV-4 in Fig. 2b), and homozygous and hemizygous wild type alleles in normal family members (individuals IV-1, III-3, IV-3, IV-5 in Fig. 2b). Patient
V-7 in Fig. 1 also carried the mutation (data not shown). RFLP analysis also showed that the p.S89F mutation was not present in 200 normal controls (100 males and 100 females). The p.S89F mutation is located in the critical transmembrane segment II of the $G$ protein-coupled receptor (Fig. 2c). The p.S89F mutation occurs at a residue that is evolutionarily highly conserved from Xenopus and fish to humans (Fig. 2d). These results strongly suggest that the p.S89F change is a pathogenic mutation for the disease in the family.

\section{Discussion}

We have identified and characterized a six-generation Chinese family with $\mathrm{X}$-linked recessive nystagmus in all patients and foveal hypoplasia in some patients (Fig. 1A). Linkage analysis with markers covering the entire $\mathrm{X}$ chromosome and follow-up haplotype analysis mapped the disease gene on chromosome Xp22. Mutation analysis identified a novel p.S89F mutation in the GPR143 gene. No mutation was identified in twenty other candidate genes analyzed. These results strongly suggest that the p.S89F mutation causes the disease in the family.

The GPR143 gene (or OA1) consists of nine exons and encodes a 439-kDa protein of 404 amino acids with homology to seven transmembrane segments, a $G$ proteincoupled receptor (Bassi et al. 1995). It was originally identified by positional cloning as a gene that, when mutated, caused ocular albinism, a disease characterized by absent or decreased ocular pigmentation, reduced visual acuity, and photophobia (Schiaffino et al. 1996). Although many mutations in GPR143 have been identified in patients (Camand et al. 2003; Schiaffino and Tacchetti 2005; Mayeur et al. 2006), the p.S89F mutation is the first GPR143 mutation found in the Chinese population.

The achiasma syndrome has also been observed in a patient with nystagmus (Korff et al. 2003). Misrouting of the optic fibers in some patients with ocular albinism has been revealed by use of visually evoked magnetic fields (VEFs) (Ohde et al. 2004; Lauronen et al. 2005). Functional magnetic resonance imaging (fMRI) studies of some patients with oculocutaneous albinism revealed abnormalities in the optic nerve head (Kasmann-Kellner et al. 2003; Morland et al. 2001). We performed fMRI on patient V-10 but no remarkable abnormalities were identified.

Nystagmus has been reported in ocular albinism patients with mutations in GPR143 (Preising et al. 2001). Genetic and clinical analysis revealed that the Chinese family under study has a variant phenotype of ocular albinism, because a mutation in GPR143/OAl was identified, and foveal hypoplasia and reduced visual acuity, in addition to nystagmus, were observed for some patients in the family. 
A

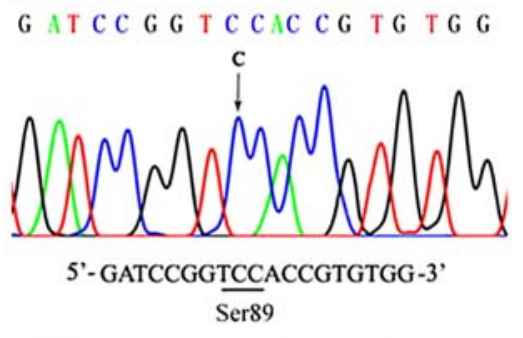

GA T C C G G T T CAC C G T G T G G

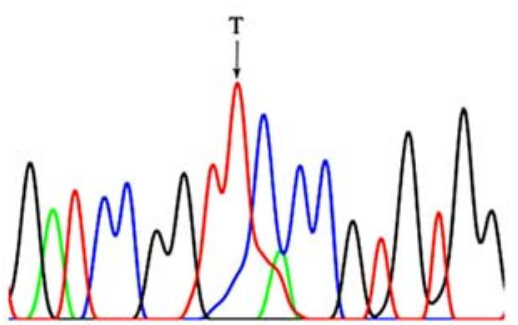

5'-GATCCGGTTCACCGTGTGG -3'

Phe89

GA T C C G G T NCAC C G T G T G G

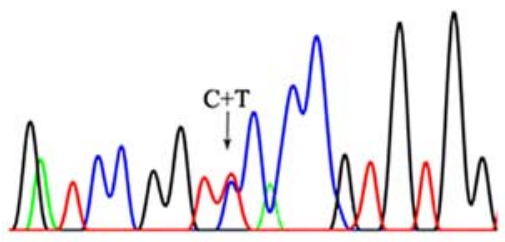

5'-GATCCGGTC/TCACCGTGTGG-3' Ser89Phe
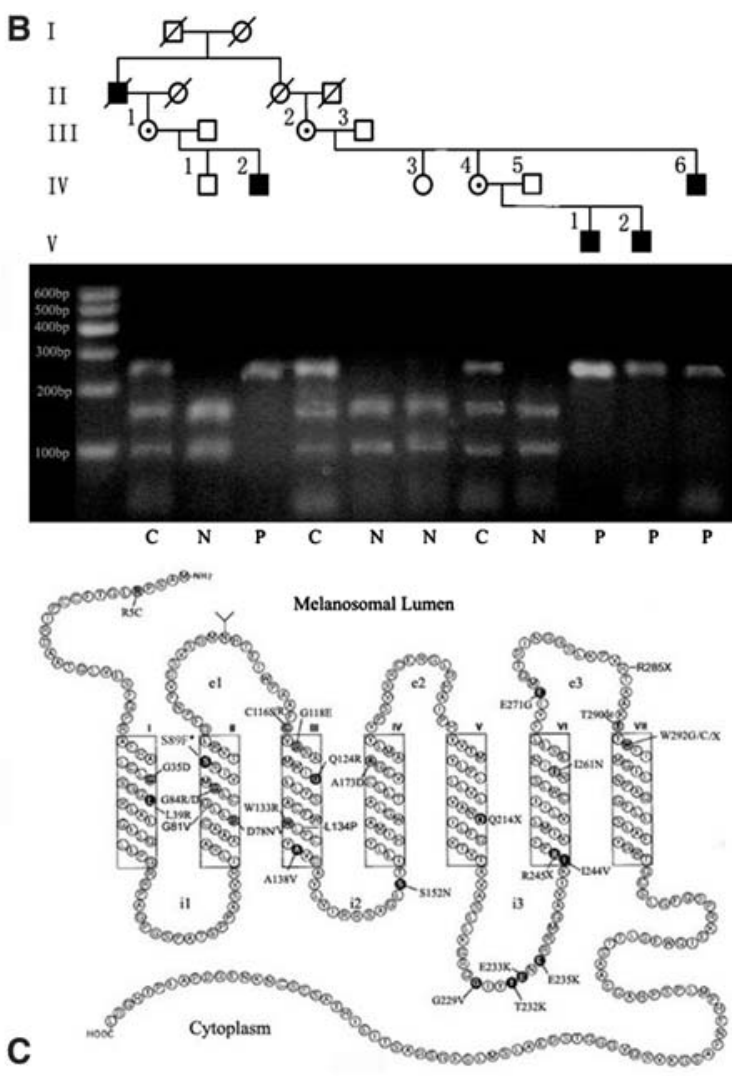

C

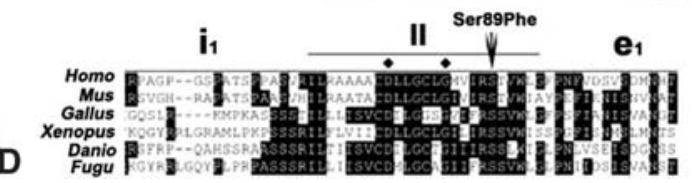

Fig. 2 a Identification of a novel mutation c.266C > T (p.S89F) in the GPR143 gene in the Chinese family with CN. DNA sequences for a normal family member (IV-9 in Fig. 1) (upper), the proband V-10 (middle), and female carrier IV-14 (bottom) are shown. The $\mathrm{C}$ to $\mathrm{T}$ change at codon 89 results in substitution of a Ser residue by a Phe residue in exon 2 of the GPR143 gene (GenBank accession number Z48804). b RFLP analysis showing that GPR143 mutation p.S89F cosegregates with nystagmus in the family. The first lane shows $100 \mathrm{bp}$ molecular weight ladder. The p.S89F mutation abolishes a BSlI restriction site. The PCR fragment was 237-bp. The wild type PCR product can be cut by BSlI, yielding two shorter DNA fragments of 143 and $94 \mathrm{bp}$. The fragment containing mutation p.S89F cannot be cut by the BSII enzyme. Separate RFLP analysis showed that individual V-7 in Fig. 1A also carried the mutation (data not shown). The PCR primers used for RFLP analysis are 237-1/forward, 5'TTTCCAAAGCAAGAAGTCAGC-3' and 237-1/reverse, 5' TGCGATTTGAGGAGCATAAG $-3^{\prime}$. c The putative structure of

None of the patients in the family had the complete classical phenotype of ocular albinism.

GPR143 is expressed mainly in pigment cells of the skin and eyes. It is located on the membrane of an intracellular organelle-the melanosomes in pigment cells-and regulates the biogenesis and maturing of melanosomes (Preising et al. 2001; Schiaffino and Tacchetti 2005). GPR143 mutations that cause ocular albinism are loss-of-function the GPR143 receptor with seven putative transmembrane $\alpha$-helices (TM I to VII) (modified from d'Addio et al. 2000). The GPR143 protein is inserted within the melanosomal membrane with the $\mathrm{N}$ terminus toward the melanosomal lumen and the C-terminus toward the cytoplasm. Hydrophilic lumenal and intracellular loops are indicated by $e_{1-3}$ and $i_{1-3}$, respectively. The location of 24 independent missense mutations and three nonsense mutations (with $\mathrm{X}$ ) identified in GPR143 are marked (from the OA1 mutation database Camand et al. 2003; Mayeur et al. 2006). The p.S89F mutation identified in this study is indicated by an asterisks and is at the second putative transmembrane $\alpha$-helix. $\mathbf{d}$ The alignment of amino acids around S89 revealed evolutionary conservation of this residue from Fugu, Danio, Xenopus, Gallus, and Mus to Homo. Dark shading indicates residues conserved in six sequences; diamonds indicate sites of missense mutations reported and identified in ocular alinism patients (Schiaffino et al. 2005). The location of the p.S89F mutation identified in this study is marked with an arrowhead

mutations, because many are deletion, frameshift, and nonsense mutations (Mayeur et al. 2006). Some GPR143 mutations had defective glycosylation and were retained in the endoplasmic reticulum (Shen and Orlow 2001). A similar phenotype to human ocular albinism patients, including hypopigmentation of the ocular fundus and the presence of giant melanosomes formed by abnormal growth of single melanosomes, has also been observed in 
knockout mice deficient in GPRl43 (Schiaffino and Tacchetti 2005).

The molecular pathogenic mechanism for nystagmus is unknown. It may result from instability of the ocular motor system (Dell'Osso and Flynn 1974). Changes in the ultrastructure of the extraocular muscle of congenital nystagmus patients have been detected by transmission electron microscopy (Peng et al. 1998). It is likely that the GPR143 mutations may disrupt a key signal-transduction pathway and cause instability in the motor system controlling the eye movement. The specific molecular mechanism by which the GPR143 p.S89F mutation causes nystagmus and foveal dysplasia is not clear, however, and future functional studies may shed light on this issue.

Acknowledgments We are grateful to the family members for their enthusiastic participation in this study, and to Xiangming Guo and Yi Xiang for advice on clinical diagnosis of $\mathrm{CN}$ and OA. This study was supported by the National High Technology " 863 " Programs of China (no. 2002BA711A07), the "Tenth Five-Year" Science and Technology Program (no. 2004BA720A), and a Chinese National Natural Science Foundation grant (no. 30670736). Q.K.W. is an Established Investigator of the American Heart Association $(0440157 \mathrm{~N})$

\section{References}

d'Addio M, Pizzigoni A, Bassi MT, Baschirotto C, Valetti C, Incerti B, Clementi M, De Luca M, Ballabio A, Schiaffino MV (2000) Defective intracellular transport and processing of OA1 is a major cause of ocular albinism type 1. Hum Mol Genet 9:30113018

Bassi MT, Schiaffino MV, Renieri A, De Nigris F, Galli L, Bruttini M et al (1995) Cloning of the gene for ocular albinism type 1 from the distal short arm of the X chromosome. Nat Genet 10:13-19

Cabot A, Rozet JM, Gerber S, Perrault I, Ducroq D, Smahi A, Souied E, Munnich A, Kaplan J (1999) A gene for X-linked idiopathic congenital nystagmus (NYS1)maps to chromosome Xp11.4p11.3. Am J Hum Genet 64:1141-1146

Camand O, Boutboul S, Arbogast L, Roche O, Stereberg C, Sutherland J et al (2003) Mutational analysis of the OA1 gene in ocular albinism. Ophthal Genet 24:167-173

Dell'Osso LF, Flynn JT, Daroff RB (1974) Hereditary congenital nystagmus: an intrafamilial study. Arch Ophthalmol 92:366-374

Gottlob I (2001) Nystagmus. Curr Opin Ophthalmol 12:378-383

Guo X, Li S, Jia X, Xiao X, Wang P, Zhang Q (2006) Linkage analysis of two families with $\mathrm{X}$-linked recessive congenital motor nystagmus. J Hum Genet 51:76-80

Kasmann-Kellner B, Schafer T, Krick CM, Ruprecht KW, Reith W, Schmitz BL (2003) Anatomical differences in optic nerve, chiasma and tractus opticus in human albinism as demonstrated by standardized clinical and MRI evaluation. Klin Monatsbl Augenheilkd 220:334-344

Kerrison JB, Arnould VJ, Barmada MM, Koenekoop RK, Schmeckpeper BJ, Maumenee IH (1996) A gene for autosomal dominant congenital nystagmus localizes to $6 \mathrm{p} 12$. Genomics 33:523-526

Kerrison JB, Koenekoop RK, Arnould VJ, Zee D, Maumenee IH (1998) Clinical features of autosomal dominant congenital nystagmus linked to chromosome 6p12. Am J Ophthal 125:6470

Kerrison JB, Vagefi MR, Barmada MM, Maumenee IH (1999) Congenital motor nystagmus linked to Xq26-q27. Am J Hum Genet 64:600-607

Klein C, Vieregge P, Heide W, Kemper B, Hagedorn-Geriwe M, Hagenah J et al (1998) Exclusion of chromosome regions 6p12 and $15 \mathrm{q} 11$, but not chromosome region $7 \mathrm{p} 11$, in a German family with autosomal dominant congenital nystagmus. Genomics 54:176-177

Korff CM, Apkarian P, Bour LJ, Meuli R, verrey JD, Roulet Perez E (2003) Isolated absence of optic chiasm revealed by congenital nystagmus, MRI and VEPs. Neuropediatrics 34:219-223

Lauronen L, Jalkanen R, Huttunen J, Carlsson E, Tuupanen S, Lindh $S$ et al (2005) Abnormal crossing of the optic fibres shown by evoked magnetic fields in patients with ocular albinism with a novel mutation in the OA1 gene. Br J Ophthalmal 89:820-824

Mayeur H, Roche O, Vetu C, Jaliffa C, Marchant D, Dollfus H et al (2006) Eight previously unidentified mutations found in the $O A 1$ ocular albinism gene. BMC Med Genet 7:41-48

Morland AB, Baseler HA, Hoffmann MB, Sharpe LT, Wandell BA (2001) Abnormal retinotopic representations in human visual cortex revealed by fMRI. Acta Psychol (Amst) 107:229-47

Ohde H, Shinoda K, Nishiyama T, Kado H, Haruta Y, Mashima Y et al (2004) New method for detecting misrouted retinofugal fibers in humans with albinism by magnetoencephalography. Vis Res 44:1033-1038

Patton MA, Jefery S, Lee N, Hogg C (1993) Congenital nystagmus cosegregating with a balanced 7;15 translocation. J Med Genet 30:526-528

Peng GH, Zhang C, Yang JC (1998) Ultrastructural study of extraocular muscle in congenital nystagmus. Ophthalmologica 212:1-4

Preising M, Op de Laak JP, Lorenz B (2001) Deletion in the OA1 gene in a family with congenital $\mathrm{X}$ linked nystagmus. $\mathrm{Br} \mathrm{J}$ Ophthalmol 85:1098-1103

Ragge NK, Hartley C, Dearlove AM, Walker J, Russell-Eggitt I, Harris CM (2003) Familial vestibulocerebellar disorder maps to chromosome 13q31-q33: a new nystagmus locus. J Med Genet 40:37-41

Schiaffino MV, Tacchetti C (2005) The ocular albinism type 1 (OA1) protein and the evidence for an intracellular signal transduction system involved in melanosome biogenesis. Pigment Cell Res $18: 227-233$

Schiaffino MV, Baschirotto C, Pellegrini G, Montalti S, Tacchetti C, De Luca M, Ballabio A (1996) The Ocular Albinism type 1 (OA1) gene product is a membrane glycoprotein localized to melanosomes. Proc Natl Acad Sci USA 93:9055-9060

Shen B, Orlow SJ (2001) The ocular albinism type 1 gene product is an $\mathrm{N}$-glycoprotein but glycosylation is not required for its subcellular distribution. Pigment Cell Res 14:485-490

Tarpey P, Thomas S, Sarvananthan N, Mallya U, Lisgo S, Talbot CJ et al (2006) Mutations in FRMD7, a newly identified member of the FERM family, cause X-linked idiopathic congenital nystagmus. Nat Genet 38:1242-1244

Wang Q, Liu M, Xu C, Tang Z, Liao Y, Du R et al (2005) Novel CACNA1S mutation causes autosomal dominant hypokalemic periodic paralysis in a Chinese family. J Mol Med 83:203-208

Zhang B, Xia K, Ding M, Liang D, Liu Z, Pan Q et al (2005) Confirmation and refinement of a genetic locus of congenital motor nystagmus in Xq26.3-q27.1 in a Chinese family. Hum Genet 116:128-131 